\title{
GAMBARAN MOTIVASI PERAWAT DALAM MELAKUKAN ASUHAN KEPERAWATAN DI RUMAH SAKIT BHAYANGKARA MANADO
}

\author{
Wenda R. Pangemanan \\ Hendro Bidjuni \\ Vandri Kallo \\ Program Studi Ilmu Keperawatan Fakultas Kedokteran \\ Universitas Sam Ratulangi Manado \\ Email :pangemanan.wenda@gmail.com
}

\begin{abstract}
Motivation is anything that encourages someone to do something. Motivation is divided into two parts, namely intrinsic motivation which is motivation that comes from within the person itself, for example, job satisfaction, capacity or ability, while extrinsic motivation is motivation that exists outside someone's self, for example, money, honor, status or position . High motivation will affect the performance of nurses at the hospital. The purpose of this research is to find out the description of nurses' motivation in conducting nursing care at Bhayangkara Manado Hospital in 2018. The research design is purely descriptive with a retrospective approach. The samples used was 37 nurses. The instruments used were questionnaire characteristics of nurses' motivation which were tested based on manual calculations. The results of the study illustrate the motivation of nurses at Bhayangkara Hospital in Manado, where the value of $n=37$ and the results are $100.00 \%$ with the most detailed results according to the age of 26-30 years compared to age 20-25 years and age 3035 years, according to sex most of them are female with 30 people compared to men, while according to education level there are more educated nurses than those educated by DIII, DIV, $S 1$ and $S 2$ and according to the length of time the work takes between 1-3 years compared to the length of work 4 - 6 years, 7-9 and 10-12 years. The conclusion is the description of nurses' motivation at Bhayangkara Manado Hospital is high.
\end{abstract}

Keywords : Motivaton, High, dan Nurse

\begin{abstract}
Abstrak :Motivasi adalah segala sesuatu yang mendorong seseorang untuk melakukan sesuatu. Motivasi terbagi dalam dua bagian yaitu motivasi Intrinsik yang adalah motivasi yang berasal dari dalam diri orang itu sendiri, misalnya, kepuasan kerja, kapasitas atau kemampuan diri, sedangkan motivasi ekstrinsik yaitu motivasi yang ada diluar diri seseorang, misalnya, uang, kehormatan, status atau jabatan. Motivasi yang tinggi akan mempengaruhi kinerja perawat di Rumah Sakit. Tujuan dalam peneliitian ini diketahui bagaimana gambaran motivasi perawat dalam melakukan asuhan keperawatan di RS Bhayangkara Manado tahun 2018. Jenis penelitian ini adalah deskriptif murni dengan pendekatan retrospektif. Sampel yang digunakan sebanyak 37 perawat. Instrumen yang digunakan kuesioner karakteristik motivasi perawat yang diuji berdasarkan perhitungan manual. Hasil penelitian gambaran motivasi perawat di RS Bhayangkara Manado diperoleh nilai $\mathrm{n}=37$ dan hasilnya $100.00 \%$ dengan rincian hasil menurut umur yang paling banyak ada pada umur 26-30 tahun dibandingkan umur $20-25$ tahun dan umur 30 - 35 tahun, menurut jenis kelamin yang paling banyak berjenis kelamin perempuan dengan jumlah 30 orang dibandingkan berjenis kelamin laki - laki, sedangkan menurut tingkat pendidikan lebih banyak berpendidikan Ners dibandingkan yang berpendidikkan DIII, DIV, S1 dan S2 dan menurut lama kerja didapatkan hasil lama kerja antara $1-3$ tahun dibadingkan lama kerja 4 - 6 tahun, 7 - 9 dan 10 - 12 tahun. Kesimpulan yaitu gambaran motivasi perawat di RS Bhayangkara Manado tinggi.
\end{abstract}

Kata Kunci : Motivasi, Tinggi dan Perawat 


\section{PENDAHULUAN}

Keperawatan adalah kegiatan pemberian asuhan kepada individu, keluarga, kelompok, atau masyarakat, baik dalam keadaan sakit maupun sehat. Pelayanan keperawatan adalah suatu bentuk pelayanan profesional yang merupakan bagian integral dari pelayanan kesehatan yang didasarkan pada ilmu dan kiat keperawatan ditujukan kepada individu, keluarga, kelompok, atau masyarakat, baik sehat maupun sakit.Perawat selama memberikan perawatan perlu memiliki motivasi yang tinggi dalam melaksanakan pelayanan asuhan keperawatan. Pengertian motivasi tidak terlepas dari kata kebutuhan, karena kebutuhan adalah suatu potensi dalam diri manusia yang perlu ditanggapi atau direspon. Tanggapan terhadap kebutuhan tersebut diwujudkan dalam bentuk tindakan untuk pemenuhan kebutuhan tersebut dan hasilnya adalah orang yang bersangkutan merasa atau menjadi puas.

Motivasi adalah karakteristik psikologis manusia yang memberi kontribusi pada tingkat komitmen seseorang (Suarli dan Bahtiar, 2009). Motivasi kerja sebagai daya dorong bagi seseorang untuk memberikan kontribusi yang sebesar-besarnya demi keberhasilan organisasi mencapai tujuannya, dengan pengertian bahwa tercapainya tujuan organisasi berarti tercapai pula tujuan pribadi para anggota organisasi yang bersangkutan, dapat disimpulkan bahwa motivasi pada dasarnya adalah interaksi seseorang dengan situasi tertentu yang dihadapinya dan merupakan suatu alasan seseorang untuk bertindak dalam rangka memenuhi kebutuhan hidupnya (Siagian, 2008). Motivasi terbagi dalam dua bagian yaitu motivasi Intrinsik yang adalah motivasi yang berasal dari dalam diri orang itu sendiri, misalnya, kepuasan kerja, kapasitas atau kemampuan diri, sedangkan motivasi ekstrinsik yaitu motivasi yang ada diluar diri seseorang, misalnya, uang, kehormatan, status atau jabatan. Motivasi yang tinggi akanmempengaruhi kinerja perawat di Rumah Sakit. Karakteristik perawat juga merupakan faktor-faktor yang mempengaruhi kinerja perawat (Nursalam, 2011).

Penelitian yang dilakukan oleh (Nitisimeto,2002), motivasi yang tinggi mempunyai pengaruh signifikan positif terhadap kinerja karyawan pada Rumah Sakit Umum daerah Kanjuruhan Malang secara parsial. Faktor yang mempengaruhi motivasi perawat yang tinggi di Rumah Sakit Umum Daerah Knjuruhan Malang yaitu pengakuan terhadap kinerja karyawan. Adapun penelitian lain yang sejalan yaitu penelitian yang dilakukan oleh (Setiadi, 2008), Studi S1 Keperawatan, Sekolah Tinggi Ilmu Kesehatan Respati Yogyakarta. Judul penelitiannya adalah "Hubungan Motivasi Kerja Perawat dan Pelaksanaan Asuhan Keperawatan di Ruang Medikal Bedah RSUD Kota Yogyakarta". Dalam penelitian ini yang menjadi aspek utama dalam pembahasan adalah tentang motivasi kerja perawat dan pelaksanaan asuhan keperawatan. Hasil dari penelitian ini adalah ada hubungan yang signifikan antara motivasi perawat dan pelaksanaan asuhan keperawatan di ruang Medikal Bedah RSUD Kota Yogyakarta.

Penelitian yang dilakukan oleh (Miladiyah, dkk 2015) mendapatkan bahwa proporsi perawat yang mempunyai motivasi baik dan menunjukkan kinerja yang baik dalam pelaksanaan dokumentasi asuhan keperawatan adalah sebesar $72,7 \%$. Hasil uji statistik terdapat hubungan antara motivasi dan kinerja perawat dalam pelaksanaan dokumentasi asuhan keperawatan. Hasil penelitian ini menunjukkan bahwa motivasi kerja merupakan faktor yang dapat meningkatkan kinerja secara konstruktif.

Hasil penelitian (Hanan, A.A 2009), didapatkan faktor jenis kelamin, status perkawinan, tingkat pendidikan dan lama kerja memilii hubungan dengan motivasi kinerja perawat. Penelitian (Kanestren, M.S.P 2009), menyatakan bahwa variabel karakteristik individu (umur, lama kerj dan tingkat pendidikan) memiliki hubungan 
bermakna dengan kinerja perawat.Perawat dikatakan professional apabila ia bertanggungjawab atas kinerja yang diberikan, Kinerja perawat yang dimaksud adalah dapat mengimplementasikan baik wewenang, tugas dan tanggung jawabnya untuk mencapai tujuan pokok profesi serta mewujudkan tujuan dan sasaran pelayanan kesehatan (Faizin dan Winarsih, 2008).

\section{METODE PENELITIAN}

Penelitian ini menggunakan jenis penelitian deskriptif murni. Pendekatan yang dilakukan adalah pendekatan Retrospektif (Retrospective Study) yaitu suatu penelitian analitik yang menyangkut bagaimana faktor risiko dipelajari berupa pengamatan terhadap peristiwa - peristiwa yang telah terjadi bertujuan untuk mencari faktor yang berhubungan dengan penyebab.

Penelitian ini dilaksanakan di Rumah Sakit Bhayangkara Manado. Penelitian telah dilaksanakan pada bulan November Desember 2018. Populasi dalam penelitian ini adalah perawat pelaksana di ruangan rawat inap Rumah Sakit Bhayangkara Manado. Teknik pengambilan sampel dalam penelitian ini menggunakan teknik Accidental Samplingdimana pengambilan sampel berdasarkan kebetulan, bertemu atau ditemui cocok sebagai sumber data (Sugiyono 2009). Jumlah sampel dalam penelitian ini yaitu 37 sampel. Instrumen yang digunakan adalah kuesioner motivasi perawat.

Kuesioner motivasi perawat terdiri dari 28 pertanyaan. Skala pengukuran menggunakan skala ordinal dengan pilihan jawaban : Sangat Setuju $=5$; Setuju $=4$; Kurang Setuju 3; Tidak Setuju $=2$; Sangat Tidak Setuju 1. Dengan kriteria penilaian rendah $>70$ dan tinggi $\geq 70$. Data yang terkumpul diolah dan dianalisis dengan menggunakan program analisa data manual.

Tahapan dalam mendapatkan data yang benar dan mempermudah proses pengolahan data, dilakukan tahapan editing, coding, tabulating, cleaning. Analisis data dalam penelitian ini yaitu analisis univariat.
Analisis univariat dilakukan terhadap setiap variabel untuk mengetahui karakteristik setiap variabel. Penelitian dilakukan dengan menganalisis variabel yang ada secara deskriptif dengan menghitung distribusi frekuensi dan proporsinya (Sugiharto, 2012). Dalam melakukan penelitian, harus diperhatikan masalah - masalah etika penelitian yang meliputi : Informed Consent berisi pernyataan persetujuan sebagai subyek, yang diisi secara sukarela oleh subjek penelitian; Anonimity (Tanpa Nama) untuk menjaga privasi dan kerahasiaan subjek penelitian; dan Confidentiality menjaga informasi dan hasil penelitian dari orang yang tidak berhak mengakses kerahasiaan informasi responden (Nursalam, 2008).

\section{HASIL dan PEMBAHASAN}

Tabel 1. Distribusi Frekuensi Menurut Usia

\begin{tabular}{ccc}
\hline Karakteristik Usia & $\mathbf{n}$ & $\mathbf{\%}$ \\
\hline $20-25$ tahun & 9 & 24,33 \\
$26-30$ tahun & 20 & 54,05 \\
$31-35$ tahun & 8 & 30 \\
\hline Total & $\mathbf{3 7}$ & $\mathbf{1 0 0}$ \\
\hline
\end{tabular}

Sumber : Data Primer, 2018

Jumlah responden pada table 1, yang paling banyak adalah responden yang berusia 26 30 tahun yaitu 20 orang $(54,05 \%)$, sedangkan responden yang paling sedikit yaitu kelompok umur 31 - 35 tahun sebanyak 8 orang $(21,62 \%)$.

Tabel 2. Distribusi Frekuensi Menurut Jenis Kelamin

\begin{tabular}{ccc}
\hline $\begin{array}{c}\text { Karakteristik } \\
\text { Jenis Kelamin }\end{array}$ & n & \% \\
\hline Laki-Laki & 7 & 18,92 \\
Perempuan & 30 & 81,08 \\
\hline Total & $\mathbf{3 7}$ & $\mathbf{1 0 0}$ \\
\hline
\end{tabular}

Sumber: Data Primer, 2018

Data yang dipaparkan pada tabel 2, dari 37 responden, jenis kelamin responden terbanyak berjenis kelamin perempuan yaitu sebanyak 30 orang $(81,08 \%)$, 
sedangkan berjenis kelamin laki-laki berjumlah 7 orang $(18,92 \%)$

Tabel 3. Distribusi Frekuensi Menurut Tingkat Pendidikan

\begin{tabular}{ccc}
\hline $\begin{array}{c}\text { Karakteristik } \\
\text { Pendidikan }\end{array}$ & n & \% \\
\hline D III & 4 & 10,82 \\
D IV & 2 & 5,40 \\
S1 & 5 & 13,51 \\
Ners & 25 & 67,57 \\
S2 & 1 & 2,70 \\
\hline Total & $\mathbf{3 7}$ & $\mathbf{1 0 0}$ \\
\hline
\end{tabular}

Sumber : Data Primer, 2018

Distribusi tabel 3, pendidikan responden terbanyak berpendidikan Ners, yaitu sebanyak 25 orang $(67,57 \%)$ dan yang paling sedikit yaitu berpendidikan S2 sebanyak 1 orang $(2,70 \%)$.

Tabel 4. Distribusi Frekuensi Menurut Lama Kerja

\begin{tabular}{ccc}
\hline $\begin{array}{c}\text { Karakteristik } \\
\text { Lama Kerja }\end{array}$ & $\mathbf{n}$ & $\mathbf{\%}$ \\
\hline $1-3$ & 18 & 48,65 \\
$4-6$ & 12 & 32,43 \\
$7-9$ & 6 & 16,22 \\
$10-12$ & 1 & 2,70 \\
\hline Total & $\mathbf{3 7}$ & $\mathbf{1 0 0}$ \\
\hline
\end{tabular}

Sumber : Data Primer, 2018

Tingkatan lama kerja responden Pada table 4, lama kerja terbanyak yaitu, antara $1-3$ tahun $(48,65 \%)$, dan paling sedikit yaitu 10 -12 tahun $(2,70 \%)$.

Tabel 5. Distribusi Gambaran Motivasi Perawat

\begin{tabular}{ccc}
\hline $\begin{array}{c}\text { Motivasi } \\
\text { Perawat }\end{array}$ & $\mathbf{n}$ & $\mathbf{\%}$ \\
\hline Tinggi & 37 & 100 \\
Rendah & 0 & 0 \\
\hline Total & $\mathbf{3 7}$ & $\mathbf{1 0 0}$ \\
\hline
\end{tabular}

Sumber : Data Primer, 2018
Berdasarkan data pada tabel 5, denagan jumlah responden yang ada diketahui motivasi perawat tinggi.

\section{Karakteristik Responden}

Hasil penelitian yang dilakukan didapatkan bahwa sebagian besar umur responden terbanyak berumur 26 - 30 tahun $(54,05 \%)$. Hasil penelitian yang dilakukan oleh (Hasmoko, Emanuel Vensi 2008) denga judul analisis faktor - faktor yang mempengaruhi kinerja klinis perawat di ruang rawat inap Rumah Sakit Panti Wilasa Citarum Semarang bahwa kemampuan dan keterampilan seseorang dapat dihubungkan dengan umur, karena semakin lama umur seseorang maka pemahaman dan pengetahuan terhadap masalah akan lebih dewasa dalam tindakan. Sejalan dengan penelitian (Roatib, 2007) yang menyimpulkan bahwa ada hubungan yang bermakna antara usia perawat dengan motivasi perawat. Dari enelitian yang dilakukan menunjukkan bahwa responden terbanyak adalah perempuan dengan jumlah sebanyak 30 orang $(81,08 \%)$. Berdasarkan jumlah kuantitas penduduk di dunia, masih didominasi oleh kaum perempuan. Sampai saat ini juga pekerjaan atau profesi sebagai perawat masih identik dengan pekerjaan yang layak dilakukan oleh kaum perempuan, mengingat profesi ini sangat membutuhkan jiwa penyayang, membutuhkan kesabaran yang tinggi dan naluri keibuan. Tokoh - tokoh perempuan sangat menonjol dalam dunia keperawatan contohnya Florence Nightingale yang adalah pelopor perawat modern (The Lady With The Lamp). Terdapat perbedaan kemampuan antara pria dan wanita dalam hubungan antar manusia dimana wanita memiliki kepekaan yang lebih tinggi dibandingkan dengan pria (Edyana, 2008).

Pendidikan responden terbanyak berpendidikan Ners dengan jumlah sebanyak 25 orang $(67,5 \%)$. Pendidikan sangat erat hubungannya dengan pengetahuan seseorang. Menurut (Gatot dan Adisasmito, 2005) bahwa semakin tinggi tingkat pendidikan maka akan 
semakin tinggi keinginan untuk memanfaatkan pengetahuan dan keterampilan. Pendidikan keperawatan mempunyai pengaruh besar terhadap kualitas pelayanan keperawatan.

Penelitian tentang lama kerja didapatkan hasil responden terbanyak antara $1-3$ tahun $(48,65 \%)$. Lama kerjaturut menentukan kinerja sesorang dalam menjalankan tugas. Lama kerja seorang tenaga kesehatan untuk melakukan jenis pekerjaan tertentu dinyatakan dalam lamanya waktu selama melaksanakan tugas tersebut. Semakin lama seseorang bekerja, maka keterampilan dan pengalamannya juga akan semakin meningkat (Robbins, S.P. 2008). Dalam penelitian (Maslita 2017) didapatkan hasil bahwa semakin lama masa kerja, produktivitas kinerja perawat menjadi kurang baik. Hal ini tentunya dapat dipengaruhi oleh beberapa faktor seperti faktor intrinsik dan faktor ekstrinsik. Seperti dalam (Pabundu 2006) yang menyatakan bahwa seseorang yang baru memasuki lingkungan kerja akan berusaha lebih baik untuk melakukan semua hal yang menjadi tanggung jawabnya sehingg prodiktivitas kerjanya pun lebih baik.

\section{Gambaran Motivasi Perawat}

Berdasarkan penelitian penelitian yang telah dilakukan, diperoleh gambaran motivasi sebagian besar perawat tinggi dalam melakukan asuhan keperawatan di Rumah Sakit Bhayangkara Manado. Motivasi perawat yang tinggi di Rumah Sakit Bhayangkara Manado termasuk dalam bentuk motivasi Intrinsik, yaitu motivasi yang datang dari individu itu sendiri berdasarkan karakteristik umur, jenis kelamin, tingkat pendidikan dan lama kerja. Kematangan umur seseorang berpengaruh terhadap motivasi orang tersebut dalam bekerja, begitu pula dengan jenis kelamin dimana pada keadaan tertentu, jenis kelamin berpengaruh terhadap motivasi kerja yang tinggi. Tingkat pendidikan perawat juga dapat mempengaruhi motivasi kerja perawat tersebut dimana semakin tinggi tingkat pendidikan maka akan semakin tinggi keinginan perawat untuk memanfaatkan pengetahuan dan keterampilannya.Begitu juga dengan hasil penelitian yang dilakukan dimana gambaran sebagian besar motivasi perawat yang tinggi dalam melakukan asuhan keperawatan di Rumah Sakit Bhayangkara Manado dikarenakan sebagian besar perawat berpendidikan Ners. Begitu juga dengan lama kerja perawat turut menentukan tinggi rendahnya motivasi perawat dalam bekerja. Seperti halnya perawat di Rumah Sakit Bhayangkara Manado yang memiliki pengalaman lama kerja paling banyak $1-3$ tahun.

Motivasi merupakan kondisi yang berpengaruh membangkitkan, mengarahkan, dan memelihara perilaku yang berhubungan dengan lingkungan kerja (Mangkunegara, 2005). Motivasi perawat yang tinggi di Rumah Sakit Bhayangkara Manado sangat berpengaruh positif terhadap mutu pelayanan di rumah sakit tersebut. Hasil penelitian ini sejalan dengan penelitian yang dilakukan oleh (Nitisimeto 2002), dimana motivasi yang tinggi mempunyai pengaruh signifikan positif terhadap kinerja karyawan pada Rumah Sakit Umum daerah Kanjuruhan Malang secara parsial. Faktor yang mempengaruhi motivasi perawat yang tinggi di Rumah Sakit Umum Daerah Knjuruhan Malang yaitu pengakuan terhadap kinerja karyawan.

(Robbins 2008), menyatakan bahwa karakteristik individu seperti umur, masa kerja dan status pernikahan dapat mempengaruhi kinerja individu. Menurut hasil penelitian (Kanestren, M.S.P. 2009), variabel karakteristik individu (umur, lama kerja dan tingkat pendidikan) memiliki hubungan bermakna dengan kinerja perawat.Walaupun mempunyai motivasi yang tinggi, bentuk motivasi ekstrinsik dan motivasi terdesak juga mempengaruhi tinggi rendahnya motivasi perawat. Dari hasil penelitian juga didapatkan bahwa ada 2 orang perawat yang masih kurang setuju 
dengan masalah gaji yang diterima yang belum sesuai dengan beban kerja sebagai perawat pelaksana, ada juga 2 orang perawat yang kurang setuju dengan masalah penetapan gaji yang diterima yang belum sesuai dengan masa kerja perawat pelaksana. Walaupun demikian, motivasi perawat yang tinggi di Rumah Sakit Bhayangkara dapat dijadikan sebagai satu kekuatan dalam tindakan melakukan asuhan keperawatan sebagai perwujudan dari profesi perawat itu sendiri. Motivasi yang dimaksud ialah motivasi yang berasal dari dalam diri individu itu sendiri. Dengan adanya motivasi dari dalam diri sendiri seseorang dapat melakukan serangkaian kegiatan termasuk perawat pada umumnya dalam melakukan asuhan keperawatan.

Walaupun gaji yang diterima perawat di Rumah Sakit Bhayangkara Manado belum sesuai dengan beban kerja dan masa kerja perawat, mereka tetap memiliki motivasi yang tinggi dalam melakukan asuhan keperawatan di Rumah Sakit Bhayangkara Manado. Perawat yang professional harus memiliki kinerja yang baik dalam melakukan tindakan keperawatan.

\section{SIMPULAN}

Gambaran motivasi perawat di RS Bhayangkara Manado menurut tingkatan umur paling banyak berumur 26 - 30 tahun, lebih banyak perawat memiliki motivasi tinggi. Gambaran motivasi perawat di RS Bhayangkara Manado menurut jenis kelamin, paling banyak berjenis kelamin perempuan. Gambaran motivasi perawat di RS Bhayangkara Manado menurut tingkatan pendidikan paling banyak berpendidikan Ners, lebih banyak perawat memiliki motivasi yag tinnggi. Gambaran motivasi perawat di RS Bhayangkara Manado menurut lama kerja 1 - 3 tahun, lebih banyak perawat memiliki motivasi yang tinggi.

\section{DAFTAR PUSTAKA}

Edyana, A. (2008) Faktor yang berhubungan dengan kemampuan perawat pelaksana dalam menerapkan teknik komunikasi terapeutik di RSJ Bandung dan Cimahi. Tesis. Depok : FIK-UI.

Faizin dan Winarsih. (2008). Hubungan Tingkat Pendidikan dan Lama Kerja Perawat dengan Kinerja Perawat di RSU Pandan Arang Kabupaten Boyolali. Berita Ilmu Keperawatan ISSN. 1979-2397.vol. I No. 3 September 2008.

Gatot, Dewi Basmala dan Wiku Adisasmito, (2005). Hubungan Karakteristik Perawat, Isi Pekerjaan dan Lingkungan Pekerjaan Terhadap Kepuasan Kerja Perawat di Instalasi Rawat Inap RSUP Gunung Jati Cirebon. https:// www.researchgate.com

Hanan, A.A (2009). Factors affecting performance of hospital nurse in Riyadh región, Saudi Arabia. International jurnal of health care quality assurance. http://proquest.umi.com/pqdweb?did $=1636442141 \& \mathrm{Fmt}=7 \&$ clientId $=456$ $25 \& \mathrm{RQT}=309 \& \mathrm{VName}=\mathrm{PQD} \& \mathrm{cfc}=$ $\underline{1}$

Hasmoko, Emanuel Vensi (2008) Analisis Faktor - Faktor Yang Mempengaruhi Kinerja Klinis Perawat Berdasarkan Penerapan Sistem Pengembagan Menejemen (SPMKK) di Ruang Rawat Inap Rumah Sakit Panti Wilasa Citarum Semarang tahun 2008 .

Kanestren, M.S.P. (2009). Analisis hubungan karakteristik individu dan lingkungan kerja dengan kinerja perawat di unit rawat inap RS Pertamina Jaya. Tesis Fakultas Kesehatan Masyarakat Universitas Indonesia Jakarta. http://www.lontar.ui.ac.id 
Mangkunegara, Anwar Prabu. (2005). Manajeen Sumber Daya Manusia Perusahaan. Bandung : PT. Remaja Rosdakarya.

Maslita, Karen. (2017). Gambaran Kinerja Perawat Pelaksana di Ruang Rawat Inap Rumah Sakit Umum Kabupaten Tangerang.

Miladiyah, N. R., Mustikasari dan D..Gayatri. 2015. Hubungan Motivasi dan Komitmen Organisasi dengan Kinerja Perawat dalam Pelaksanaan Dokumentasi Asuhan Keperawatan. Jurnal Keperawatan Indonesia 18 (1): 9-16

Nitisimeto, 2002, Manajemen Personalia, Jakarta : Ghalia Indonesia.

Nursalam, 2008. Konsep dan Penerapan Metodologi Penelitian Ilmu Keperawatan : Jakarta : Salemba Medika.

Nursalam. 2011. Manajemen Keperawatan, Aplikasi dalam Praktik Keperawatan Profesional Edisi ke 3. Salemba. Jakarta.

Pabundu, H. Moh Tika (2006). Budaya dan Organisasi Peningkatan Kerja Perusahaan. Jakarta : Bumi Aksara.

Roatib, dkk (2007). Hubungann Antara Karakteristik Perawat dengan Motivasi Perawat Pelaksana dalam Menerapkan Komunikasi Terapeutik Pada Fase Kerja di Rumah Sakit Islam Sultan Agung Semarang. Jurnal Keperawatan Media Ners, Vol.1. Nomor 1, 43-47. Semarang : Program Studi Ilmu Keperawatan Universitas Diponegoro.

Robbins, S.P. 2008. Perilaku Organisasi, Edisi Duabelas, Penerbit Salemba Empat: Jakarta

Setiadi, Agus (2008)’ Hubungan Motivasi Kerja Perawat dan Pelaksanaan
Asuhan Keperawatan di Ruang

Medikal Bedah RSUD Kota

Yogyakarta. https://id.scribd.com

Siagian, Sondang. P. 2008. Manajemen

Sumber Daya Manusia (Edisi

Pertama). Jakarta: Binapura Aksara.

Suarli, S \& Bachtiar. (2009). Manajemen

Keperawatan Dengan Pendekatan

Praktis, Penerbit Erlangga, Jakarta.

Sugiharto., B. A. Keliat dan T. Sri. 2012. Manajemen Keperawatan: Aplikasi MPKP di Rumah sakit. EGC. Jakarta.

Sugiyono, 2009. Metode Penelitian Kuantitatif, Kualitatif dan R\&D, Bandung : Alfabeta 